\title{
Rare Occurrence of Synovial Sarcoma Originating from Dura Mater
}

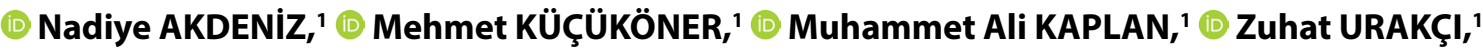 \\ (1) Halis YERLiKAYA, ${ }^{1}$ (D) Oğur KARHAN,' (1) Fatma TEKE, ${ }^{2}$ (1) Abdurrahman IŞıKDOĞAN' \\ 'Department of Medical Oncology, Dicle University, Faculty of Medicine, Diyarbakır-Turkey \\ ${ }^{2}$ Department of Radiation Oncology, Dicle University, Faculty of Medicine, Diyarbakır-Turkey
}

\begin{abstract}
SUMMARY
Primary or metastatic dura mater sarcomas are rarely seen, and dural synovial sarcomas are quite rare. Here we report the case of a 60 -year-old man who presented with headache, nausea, and vomiting and was found to have a $63 \times 33 \times 40-\mathrm{mm}$ mass with solid and cystic components in parieto-occipital lobe. The mass was resected completely, with no residue detected on postoperative magnetic resonance imagining. On pathological evaluation, a vimentin-, S100-, transducer-like enhancer of split 1-, BCL-2-, and EMApositive and desmin-, PR-, CD99-, PANCK-, and GFAP-negative synovial sarcoma with Ki-67 proliferation index of $12 \%$ was detected. Postoperatively, chemotherapy has been started, and it will be followed by radiotherapy. Primary meningeal-derived sarcomas are rare, and differential diagnosis with other meningeal mesenchymal tumors is based on the findings of morphological and immunohistochemical analyses.

Keywords: Dura mater; rare tumor; synovial sarcoma.

Copyright $\odot$ 2019, Turkish Society for Radiation Oncology
\end{abstract}

\section{Introduction}

Dura mater-originated neoplasms comprise a wide range of primary and metastatic tumors based on their clinical, radiological, morphological, and immunophenotypical features. Treatment decision is based on tumor origin, morphologic type, and degree. Primary and metastatic dura mater tumors are rarely seen, and dural synovial sarcomas are quite rare.[1] There have been few reports on dura mater-originated synovial sarcoma; here we report the case of a patient with primary dural synovial sarcoma.

\section{Case Report}

A 60-year-old woman presented to us with nausea, headache, and vomiting. No abnormalities were de- tected on neurological examination, and her biochemical parameters were within normal range. Contrastenhanced magnetic resonance imagining revealed a parieto-occipital mass $63 \times 33 \times 40-\mathrm{mm}$ in diameter with a cystic and solid component and peripheral vasogenic edema that had caused right lateral ventricle compression (Fig. 1). The mass was resected completely, and no residue was detected on postoperative MRI.

Differential diagnosis of dural-origin fusiform and epitheloid tumors comprises hemangiopericytoma, fibrous meningioma, and synovial sarcoma. In the present case, on immunohistochemical examination, the tumor was found to be positive for vimentin, S100, NSE, transducer-like enhancer of split (TLE)-1, BCL-2, EMA, FactorXIIIa, and CD34 and negative for CD30, LCA, desmin, PR, STAT-6, CD99, pancytoceratine, 

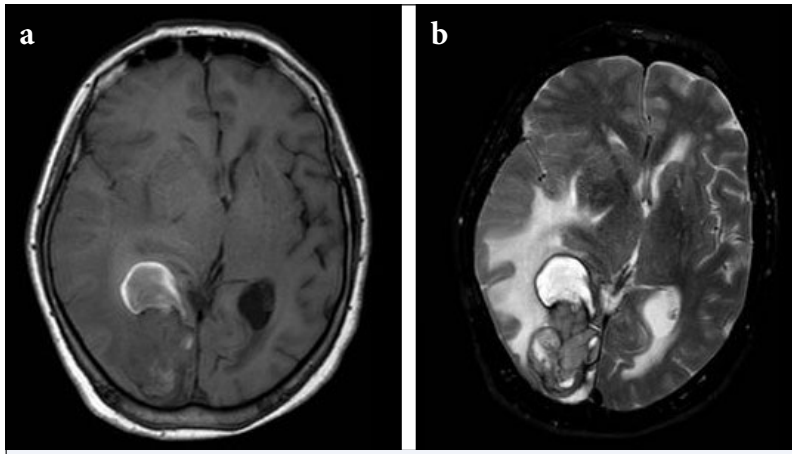

Fig. 1. Right temporo-occipital lobe mass; (a) T1Aweighted images show an isointense mass comprising hyperintense hemorrhagic necrotic areas (b) T2A sequence demonstrates "triple sign" (hyperintense necrotic areas compatible with a triple sign), cystic degenerated areas of higher intensity," and hypointense linear appearance concordant with a fibrosis band.

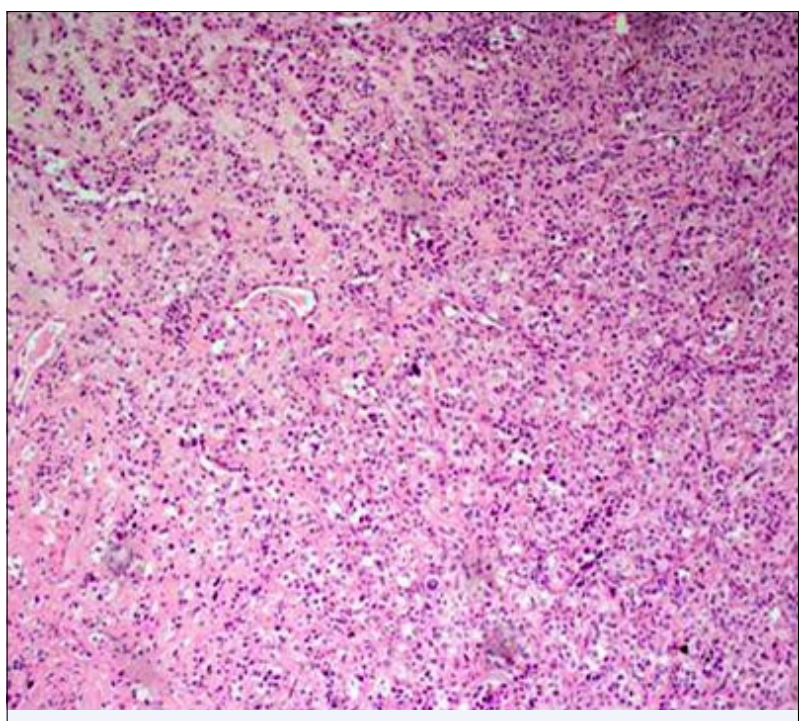

Fig. 2. Eosinophilic pleomorphic tumor cells with clear nucleoli and poorly differentiated cytoplasm borders seen in hyalinized tissue.

GFAP, and HMB-45. Ki-67 proliferation index was $12 \%$. Based on these findings, the tumor was classified as poorly differentiated dural synovial sarcoma (Fig. 2). Positron emission tomography computed tomography (PET CT) was performed for detecting metastasis; besides the primary lesion, no other lesion was detected. The patient was treated with adjuvant chemotherapy comprising ifosfamide, $2500 \mathrm{mg} / \mathrm{m}^{2}$; mesna, $2500 \mathrm{mg} /$ $\mathrm{m}^{2}$; and doxorubicin $60 \mathrm{mg} / \mathrm{m}^{2}$ for 3 consecutive days every 21 days. Cranial radiotherapy has been planned for the patient after chemotherapy.

\section{Discussion}

Synovial sarcomas comprise $5 \%-10 \%$ of soft tissue sarcomas.[2] The occurrence of head and neck synovial sarcomas is even less, and they comprise 3\%-5\% of total sarcomas. Slight female predominance is seen, with the woman to man ratio being $1,6: 1 .[3,4]$ These tumors are mostly observed in individuals aged 15-35 years; however, their occurrence may range from being present at birth until the age of 89 years.[2]

Synovial sarcomas are not derived from synovium; they originate from primitive mesenchymal stem cells and can be seen in regions without synovium. [5] Synovial sarcomas are mostly seen on extremities; however, they may be distributed widely across the head and neck, mediastinum, abdomen, lung, pleura, kidney, and gastrointestinal tract.[6] These tumors have been reported to exist intracranially in the dura mater and base of the skull, indicating that they may be present anywhere in the body.[7]

Clinical presentation of meningothelial mesenchymal tumors includes their anatomic location and diameter. The affected patients mostly present with nausea, vomiting, headache, paresthesia, memory impairment, convulsions, disequilibrium, aphasia, and hearing loss. Neuroradiological examination has reportedly revealed meningeal-originated tumor and a range of dissemination. [8]

The appearance of these tumors is related to differentiation and resembles extracranial soft tissue sarcomas. Rapidly progressive tumors are poorly demarcated, fragile, hemorrhagic, necrotic, and cystic. [9] Histologically, synovial sarcomas are differentiated into four subtypes: monophasic, monophasic epithelial, biphasic, and poorly differentiated types. $[10,11]$ The present case was classified as poorly differentiated synovial sarcoma because cystic, solid component and intratumoral hematoma were observed.

Based on the location and morphological features, the tumor in the present case was histopathologically different from meningioma, solitary fibrous tumor, and others sarcomas.[12] In addition to $100 \%$ immunoreactivity for EMA, 86\%-90\% nuclear positivity $\mathrm{PgR}$ is observed in meningiomas. $[13,14]$ In the present case, contrary to EMA positivity, PgR was negative. Solitary fibrous tumors may also be located in central nervous system. They are negative for cytokeratin and EMA, while diffuse positivity is observed with CD34.[2] Although the present case was positive for CD34 and negative for cytokeratin, positive immunoreaction for EMA was inconsistent with the solitary fibrous tumor. Approximately $10 \%-20 \%$ 
of synovial sarcomas have the same pattern as hemangiopericytomas.[1] Like peripheral nerve sheath tumors, $30 \%$ of monophasic and poorly differentiated synovial sarcomas show nuclear and cytoplasmic S100-positive immunoreaction.[15] The immune reaction to EMA and cytokeratin is negative in malign peripheral nerve sheath tumors; thus, these tests may be used in differential diagnosis.[16] In the present case, similar to malign peripheral nerve sheath tumors, S-100 was immunoreactive, but unlikely EMA was immunoreactive either. Recently, high expression of TLE-1 has been observed in synovial sarcomas. In the present case, TLE immunoreactivity was positive; this feature is specific and sensitive for synovial sarcomas.[17] Furthermore, in this case, Ki-67 proliferation index was $12 \%$. However, because synovial sarcoma-specific chromosomal translocation (X;18) (p11; q11) was seen, diagnosis was made based on the findings of histological and immunohistochemical tests in the present case.[9]

Dura mater and leptomeningeal synovial sarcomas are very rarely seen, so optimal systematic treatment has not been established.[9] Wide surgical resection, radiotherapy, and doxorubicin-based chemotherapy may prevent local recurrence of the tumor and improve prognosis. $[10,18,19]$

\section{Conclusion}

In conclusion, primary meningeal synovial sarcomas have been seldom diagnosed, and case-based presentations are present. They can be differentiated from mesenchymal meningeal tumors on the basis of morphological and immunohistochemical features.

Acknowledgements: The research was not financially supported by grants or any other kind of funding from any pharmaceutical company or other possible sources. All the authors had an active involvement in data collection and analysis, as well as writing, preparing and reviewing the manuscript.

Informed consent: Written informed consent was obtained from the patient for the publication of the case report and the accompanying images.

Peer-review: Externally peer-reviewed.

Conflict of Interest: The authors have no conflict of interests to declare.

Financial Disclosure: The authors declared that this study has received no financial support.

Authorship contributions: Concept - M.K.; Design H.Y.; Supervision - Z.U.; Materials - M.K.; Data collection \&/or processing - N.A., F.T.; Analysis and/or interpretation - N.A., M.A.K.; Literature search - N.A., O.K.; Writing N.A., O.K.; Critical review - A.I.

\section{References}

1. Sharma S, Sharma A, Lobo G, Nayak M, Pradhan D, Samriti, et al. Primary dura-based synovial sarcoma of the parafalcine region of brain. Pathol Res Pract 2017;213(7):868-71.

2. World Health Organization. World Health Organization Classification of Tumours. In: Fletcher CDM, Unni KK, Mertens F, editors. Pathology and genetics of tumours of soft tissue and bone. Lyon: IARC; 2002. p. 200-04.

3. World Health Organization. In: Fletcher CDM, Unni KK, Mertens F, editors. World Health Organization Classification of Soft Tissue Tumors. 4th ed. Lyon: IARC; 2013. p. 213-15.

4. Ji T, Ma CY, Ow A, Wang LZ, Sun J, Zhang CP. Synovial sarcoma involving skull base-a retrospective analysis of diagnosis and treatment of 21 cases in one institution. Oral Oncol 2011;47(7):671-6.

5. Ghadially FN. Is synovial sarcoma a carcinosarcoma of connective tissue? Ultrastruct Pathol 1987;11(23):147-51.

6. Fletcher C. Tumors of soft tissue. Diagnostic Histopathology of Tumors. In: Fletcher C, editor. 4th ed. Philadelphia: Elsevier-Saunders; 2013. p. 184749.

7. Horbinski C, Cieply K, Bejjani GK, McFadden K. Primary intracranial dural-based synovial sarcoma with an unusual SYT fluorescence in situ hybridization pattern. J Neurosurg 2008;109(5):897-903.

8. Goldblum JR, Weiss SW, Folpe AL. Malignant Soft Tissue Tumors of Uncertain Type. In: Enzinger and Weiss's Soft Tissue Tumors. 6th ed. Philadelphia: Elsevier-Saunders; 2014. p. 1052-70.

9. Lin YJ, Yang QX, Tian XY, Li B, Li Z. Unusual primary intracranial dural-based poorly differentiated synovial sarcoma with $\mathrm{t}(\mathrm{X} ; 18)(\mathrm{p} 11 ; \mathrm{q} 11)$. Neuropathology 2013;33(1):75-82.

10. Nuwal P, Dixit R, Shah NS, Samaria A. Primary monophasic synovial sarcoma lung with brain metastasis diagnosed on transthoracic FNAC: Report of a case with literature review. Lung India 2012;29(4):384-7.

11. Rajwanshi A, Srinivas R, Upasana G. Malignant small round cell tumors. J Cytol 2009;26(1):1-10.

12. Carneiro SS, Scheithauer BW, Nascimento AG, Hirose T, Davis DH. Solitary fibrous tumor of the meninges: 
a lesion distinct from fibrous meningioma. A clinicopathologic and immunohistochemical study. Am J Clin Pathol 1996;106(2):217-24.

13. Abdelzaher E, Abdallah DM. Expression of mesothelioma-related markers in meningiomas: an immunohistochemical study. Biomed Res Int 2014;2014:968794.

14. Hsu DW, Efird JT, Hedley-Whyte ET. Progesterone and estrogen receptors in meningiomas: prognostic considerations. J Neurosurg 1997;86(1):113-20.

15. Folpe AL, Schmidt RA, Chapman D, Gown AM. Poorly differentiated synovial sarcoma: immunohistochemical distinction from primitive neuroectodermal tumors and high-grade malignant peripheral nerve sheath tumors. Am J Surg Pathol 1998;22(6):673-82.

16. Smith TA, Machen SK, Fisher C, Goldblum JR. Usefulness of cytokeratin subsets for distinguish- ing monophasic synovial sarcoma from malignant peripheral nerve sheath tumor. Am J Clin Pathol 1999;112(5):641-8.

17. Foo WC, Cruise MW, Wick MR, Hornick JL. Immunohistochemical staining for TLE1 distinguishes synovial sarcoma from histologic mimics. Am J Clin Pathol 2011;135(6):839-44.

18. Guadagnolo BA, Zagars GK, Ballo MT, Patel SR, Lewis VO, Pisters PW, et al. Long-term outcomes for synovial sarcoma treated with conservation surgery and radiotherapy. Int J Radiat Oncol Biol Phys 2007;69(4):1173-80.

19. Baptista AM, Camargo OP, Croci AT, Oliveira CR, Azevedo Neto RS, Giannotti MA, et al. Synovial sarcoma of the extremities: prognostic factors for 20 nonmetastatic cases and a new histologic grading system with prognostic significance. Clinics (Sao Paulo) 2006;61(5):381-6. 